WellBeing International

WBI Studies Repository

9-1986

\title{
Cardiac Correlates of Individual Recognition in the Chimpanzee (Pan troglodytes)
}

Sarah T. Boysen

Ohio State University

Gary G. Berntson

Ohio State University

Follow this and additional works at: https://www.wellbeingintlstudiesrepository.org/acwp_asie

Part of the Animal Studies Commons, Comparative Psychology Commons, and the Other Animal

Sciences Commons

\section{Recommended Citation}

Boysen, S. T., \& Berntson, G. G. (1986). Cardiac correlates of individual recognition in the chimpanzee (Pan troglodytes). Journal of Comparative Psychology, 100(3), 321.

This material is brought to you for free and open access by WellBeing International. It has been accepted for inclusion by an authorized administrator of the WBI Studies Repository. For more information, please contact wbisr-info@wellbeingintl.org.

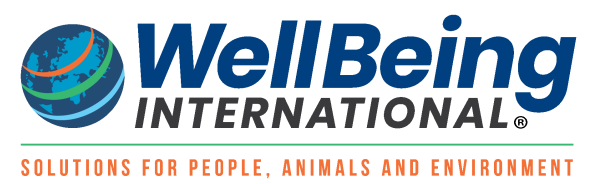




\title{
Cardiac Correlates of Individual Recognition in the Chimpanzee (Pan troglodytes)
}

\author{
Sarah T. Boysen ${ }^{1,2}$ and Gary G. Berntson ${ }^{1,2}$ \\ ${ }^{1}$ Ohio State University \\ ${ }^{2}$ Emory University
}

\begin{abstract}
The ability of a chimpanzee to recognize individuals depicted in photographs was evaluated through the use of heart rate measures. Heart rate was recorded before and during photographic projections of human caregivers, familiar individuals, strangers, and blank control slides. In the absence of explicit training or reinforcement, the chimpanzee displayed a differential pattern of heart rate response to the stimulus categories. Although heart rate responses to all stimuli were predominantly deceleratory, the photographs of caregivers yielded consistently larger responses than other stimuli. Results indicate that the chimpanzee is able to recognize individual humans from novel photographic representations and that heart rate can provide an objective measure of such recognition.
\end{abstract}

The classic studies of Harlow characterized critical dimensions of social attachment in nonhuman primates and detailed the devastating behavioral consequences of disruptions of the attachment process (Harlow \& Mears, 1979). In view of the documented significance of social interactions in primates, the ability to recognize facial features of conspecifics would seem to offer considerable survival advantage. In this regard, increasing evidence now indicates that the recognition of faces, at least in primates, may be related to specialized neuronal mechanisms. Highly selective "face-specific" neurons have recently been identified in the temporal cortex of monkeys (Perrett et al., 1984; Rolls, 1984). Further, it has been reported that damage to relatively specific neuroanatomical systems in the human can result in prosopagnosia, a condition characterized by an inability to recognize faces in the absence of generalized deficits in visual discrimination (Damasio, Damasio, \& van Hoesen, 1982; Jeeves, 1984). Related to these findings, human infants within the early months of life are able to discriminate between human faces or between photographs of faces (Barrera \& Mauer, 1981; Bushnell, 1982; Pagan \& Singer, 1979).

When given the opportunity for direct visual access to conspecifics, monkeys display a preference for viewing animals with which they have a close social bond, a finding that documents individual recognition in nonhuman primates (Sackett, Griffin, Pratt, Joslyn, \& Ruppenthal, 1967). In addition, nonhuman primates can discriminate among photographs of either conspecific or human faces (Bruce, 1982; Rosenfeld \& van Hoesen, 1979; Sands, Lincoln, \& Wright, 1982). Although these studies demonstrate discrimination among such photographs, it remains unclear whether animals can, in fact, recognize the specific individuals depicted. In order to examine the ability of nonhuman primates to recognize individuals from photographic representations, and to explore a potential objective index of individual recognition, we employed heart rate measures to evaluate the functional reactions of a chimpanzee to photographs of human faces. In the absence of explicit training or reinforcement, the chimpanzee 
displayed a differential pattern of heart rate response to photographs of human caregivers, relative to other familiar individuals or strangers.

\section{Method}

\section{Subject}

The subject was a female chimpanzee (Pan troglodytes), Sheba, 3.5 years of age at the time of the study. The animal was home reared for the first 1.5 years of life and joined our project at 2 years of age. Since her involvement in the project, Sheba has spent approximately $6 \mathrm{hr}$ each day learning a variety of cognitive skills and performance tasks in a direct interactive setting with humans. During this training, Sheba formed strong social bonds with her two primary caregivers. None of this training, however, explicitly entailed recognition of, or responding to, specific individuals or to photographs of individuals.

\section{Electrocardiographs (EKG) Measures}

Heart rate was measured by disposable silver/silver chloride electrodes attached to standard thoracic monitor sites and further secured by an elastic bandage. EKG electrodes were connected to an Amerec ERM 101 cardiotachometer, the R-wave-detector output of which was coupled to a microcomputer for online determination of individual heart periods. The raw EKG signal was also recorded on FM tape (Cardiodyne Cardiocassette) for off-line playback. Heart period values for $4 \mathrm{~s}$ before and $12 \mathrm{~s}$ after each stimulus presentation were stored for subsequent analysis. Potential artifacts in the heart period record were identified off-line by the computer system as heart periods that deviated from either of the immediately surrounding beats by more than $35 \%$. Heart period values that exceeded this criterion were verified or corrected by direct measurement from the polygraph record. The mean heart period for each second was then calculated as the average of the beats falling within that second, together with a proportionately weighted contribution from beats that partially overlapped the interval. The second-bysecond heart period values were then converted to rate.

\section{Procedure}

To explore the cardiac correlates of individual recognition in the chimpanzee, we measured heart rate response to slide presentations of human faces. Following training sessions for accommodation to the EKG electrodes, photographs of six female humans and a blank control slide were repeatedly presented to the subject over nine experimental sessions. The slide stimuli consisted of facial photographs of two primary caretakers, two familiar individuals (with whom the animal had not physically interacted), and two strangers. Stimuli were presented on a rear surface projection screen, $2 \mathrm{~m}$ from the subject $\left(20^{\circ}\right.$ of visual angle; $40 \mathrm{Ix}$ ). Each stimulus slide was presented for $8 \mathrm{~s}$, with heart rate measures obtained for $4 \mathrm{~s}$ before and $12 \mathrm{~s}$ after stimulus onset.

All testing was accomplished with the animal in a quiet alert state. During testing, the animal sat with an experimenter, who was unaware of the stimulus sequence and unable to see the projection screen. During each of the nine sessions, the six photographs were presented in a block-randomized sequence. In addition, two blank control slides were presented before, and one after, the sequence of photographs in each session. Intertrial intervals averaged $35 \mathrm{~s}$ (25-35 s, randomized).

\section{Data Analysis}

Because heart rate responses were generally monophasic, data analyses were based on the change in heart rate from the 4-s prestimulus period to the 8-s period during which the slide stimulus was presented. In order to minimize the effect of novelty related to the first slide presentation (always a blank control 
slide), the results from the first trial were excluded from analysis. This yielded a total, for each session, of two stimulus presentations of each slide category. As the data were derived from a single subject, overall differences among conditions were evaluated by the nonparametric Friedman's analysis of variance, and post hoc comparisons were tested by the Wilcoxon test. Because initial analyses revealed no significant differences between cardiac responses to the two individuals within a stimulus category, Wilcoxon Ts $(N=9)>13, p s>.05$, data from the two slides of a given category were collapsed for subsequent analyses.

Figure 1. Heart rate responses of a chimpanzee to photographs of three categories of individuals and blank control slides. (Top: Change in heart rate from baseline [in beats per minute] in response to each stimulus category. Bottom: Corresponding changes in heart period variability. Variability is indexed as the standard deviation of the individual heart periods around the phasic heart rate response baseline. Stimuli were presented [for $8 \mathrm{~s}$ ] during Blocks 1 and 2. Each data point reflects the average of 18 stimuli, presented over nine sessions.)
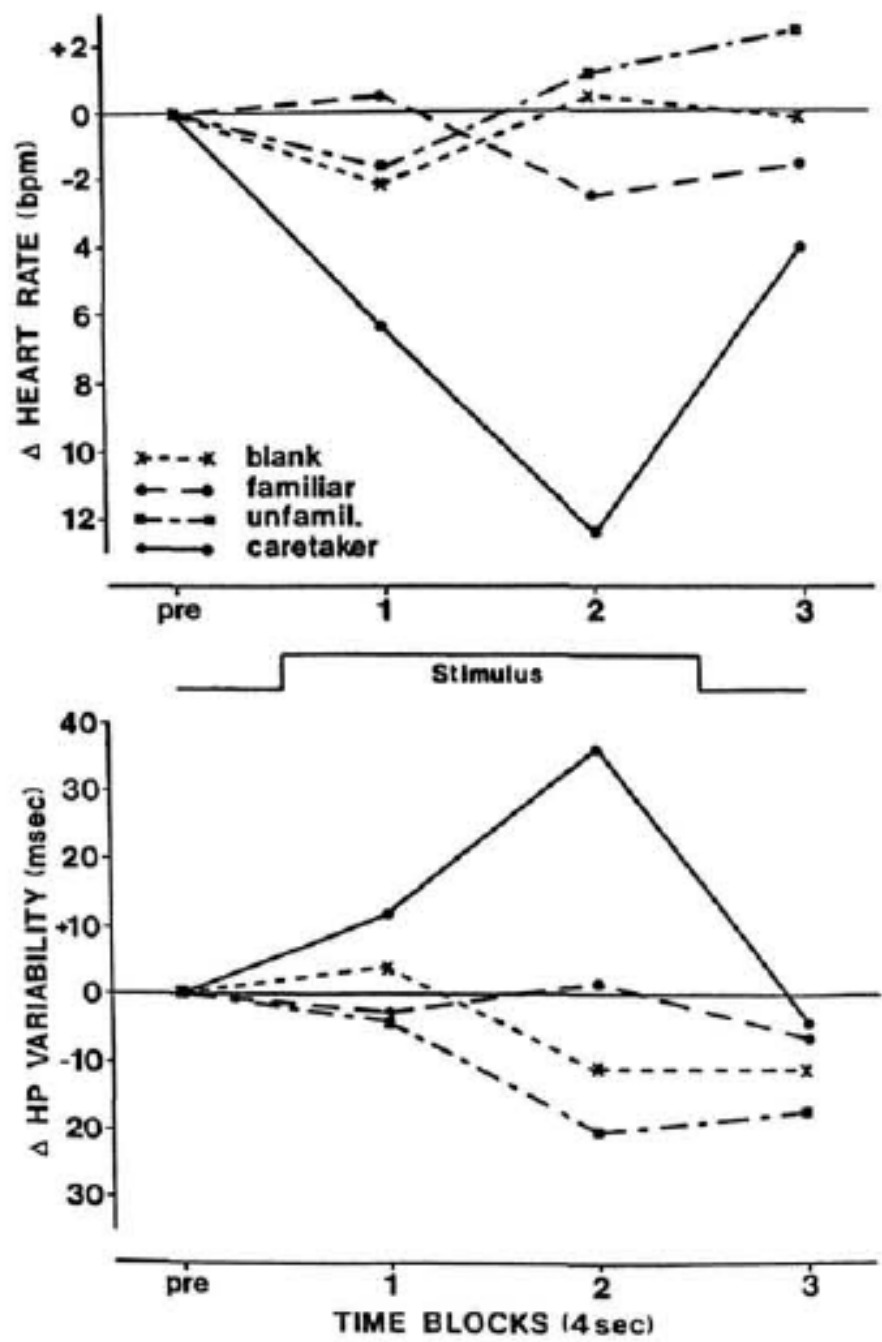

In addition, we examined the effects of stimulus presentations on heart period variability. In order to minimize the sensitivity of this measure to phasic stimulus-related changes in heart rate level, an index of variability was derived as the standard deviation of the individual beats from the expected value, based on a linear interpolation of the immediately surrounding heart periods. This index is equivalent to a 
conventional standard deviation measure except that the variability was measured around the momentary heart rate level rather than from the overall mean heart period. Statistical analyses of these data followed the procedures outlined above.

\section{Results}

Heart rate responses to the slide stimuli were predominately deceleratory, as illustrated in Figure 1. Considerable differences were apparent in the magnitude of cardiac responses across stimulus categories, however, with the photographs of caregivers yielding consistently larger responses than other stimuli. The baseline heart rate during the prestimulus periods did not differ significantly across experimental conditions (prestimulus heart rate on trials with blank control slides $=118.0$ beats per minute $[\mathrm{bpm}]$, caregivers $=120.3$, familiar individuals $=119.5$, strangers $=117.0)$, Friedman's test, $X^{2}(3, N=9)=$ 4.33, ns. In contrast, significant differences emerged across slide categories in the poststimulus heart rate responses, Friedman's test, $X^{2}(3, N=9)=8.07, p=.04$. Further analyses indicated that this difference was related to the significantly larger responses to the slides of caregivers relative to all other stimulus categories. The larger cardiac responses observed to the caregiver category appeared consistently over sessions and were apparent to each of the individual slides in this category. The mean change in heart rate during stimulus presentations was $-9.4 \mathrm{bpm}( \pm 2.2 \mathrm{SE})$ for the slides of caregivers $(-9.2$ and -9.8 for the two slides in this category). In contrast, responses were $-0.7 \mathrm{bpm}( \pm 2.2)$ for the blank control slides, Wilcoxon's $T(N=9)=3, p=.02,-1.2 \mathrm{bpm}( \pm 1.8)$ for the slides of familiar individuals, Wilcoxon's $T(N=$ $9)=4, p=.04$, and $-0.3 \mathrm{bpm}( \pm 3.0)$ for the slides of strangers, Wilcoxon's $T(N=9)=3, p=.02$. No other group comparisons achieved significance.

The differential heart rate response across stimulus categories was also apparent in measures of heart period variability (Figure 1). Whereas heart period variability did not differ across stimulus categories in the prestimulus period, Friedman's $x^{2}(3, N=9)=3.0$, ns, significant differences emerged in the poststimulus measures, Friedman's $X^{2}(3, N=9)=7.53, p=.04$. Further analyses revealed a significant increase in heart period variability in response to the caretaker slides relative to any other stimulus category, Wilcoxon's $T s(N=9)<4$, ps $<.02$.

The differences in heart rate response across the stimulus conditions were not associated with any apparent pattern of overt somatic behavior. In one instance the animal extended her hand toward the projected photograph of a caregiver, but no other somatic responses to the stimuli were observed.

To minimize habituation to the experimental stimuli, we employed only a single presentation of a given slide per session (with the exception of the blank control slide). Consequently, although there was a slight decrease in the overall magnitude of cardiac responses across sessions, and from the first half to the last half of each session, neither of these differences achieved significance.

\section{Discussion}

The present results suggest that the chimpanzee is able to recognize individual humans from photographic representations and that heart rate provides an objective measure that can reflect the social relation between the animal and the individual depicted. These results are consistent with previous reports that autonomic measures, including heart rate, pupillary reflexes, and electrodermal responses can reflect the recognition of individuals by human infants (Banks \& Wolfson, 1967; Fitzgerald, 1968; Tranel, Fowles, \& Damasio, 1985). In the present study, differences in cardiac response to different categories of individuals were apparent in the absence of explicit training, task demands, or prior experience with the photographic stimuli. These findings confirm and extend a previous report, based on 
cross-modal object matching, that nonhuman primates can recognize novel photographic representations of real-world referents (Davenport \& Rogers, 1971).

The deceleratory heart rate responses observed to the photographic stimuli likely reflected the cardiac correlate of orienting, as orienting responses have generally been found to be associated with cardiac deceleration in humans (Graham, 1979), monkeys (Weisbard \& Graham, 1971), and apes (Berntson \& Boysen, 1984). The orienting response may not reflect a simple unitary process, however, and stimulus registration, novelty, and significance appear to interact in the determination of autonomic responses (Barry, 1982; Maltzman, 1979). In the present study, the larger cardiac responses to caregivers appeared to be dependent on the adaptive significance of the stimuli, related to the existing social bonds between the subject and her human caregivers. It is unlikely that differences in stimulus novelty or stimulus registration processes, in the absence of individual recognition, could account for the differential pattern of response to the photographs. Potential heart rate responses associated with stimulus registration should have been equated, save for stimulus significance, because the photographic stimuli were of equivalent complexity, retinal size, and photic intensity. Moreover, differences in stimuli novelty may well have contributed to the observed heart rate responses, but these effects would not adequately account for the present data. To the extent that novelty effects were manifest, they would be expected to result in larger responses to the unfamiliar faces-a result opposite that obtained.

In summary, the present results suggest that the chimpanzee, in the absence of explicit training, is able to recognize individual humans from photographic representations. Moreover, it appears that the functional response to such photographs is dependent on the established social relation between the animal and the individual depicted.

\section{References}

Banks, J. H., \& Wolfson, J. H. (1967, April). Differential cardiac response of infants to mother and stranger. Paper presented at the meeting of the Eastern Psychological Association, Boston.

Barrera, M. A., \& Mauer, D. (1981). The perception of facial expressions by the three-month-old child. Child Development, 52, 203-206.

Barry, R. J. (1982). Novelty and significance effects in the fractionation of phasic OR measures: A synthesis with traditional OR theory. Psychophysiology, 19, 28-35.

Berntson, G. G., \& Boysen, S. T. (1984). Cardiac startle and orienting responses in the great apes. Behavioral Neuroscience, 98, 914-918.

Bruce, C. (1982) Face recognition by monkeys: Absence of an inversion effect. Neuropsychologia, 20, 515-522.

Bushnell, I. W. R. (1982). Discrimination of faces by young infants. Journal of Experimental Child Psychology, 30, 298-307.

Damasio, A. R., Damasio, H., \& van Hoesen, G. W. (1982). Prosopagnosia: Anatomical basis and neurobehavioral mechanism. Neurology, 32, 331-341.

Davenport, R. K., \& Rogers, C. M. (1971). Perception of photographs by apes. Behaviour, 39, 318-320.

Pagan, J. F., \& Singer, L. T. (1979). The role of simple feature differences in infant's recognition of faces. Infant Behavior and Development, 2, 39-45.

Fitzgerald, H. E. (1968). Autonomic pupillary reflex activity during early infancy and its relation to social and nonsocial stimuli. Journal of Experimental Child Psychology, 6, 470-482.

Graham, F. K. (1979). Distinguishing among orienting, defensive, and startle reflexes. In H. D. Kimmel, E. H. van Olst, \& J. F. Orlebeke (Eds.), The orienting reflex in humans (pp. 137-167). Hillsdale, NJ: Erlbaum.

Harlow, H. F., \& Mears, C. (1979). The primate model Washington: V. H. Winston. 
Jeeves, M. A. (1984). The historical roots and recurring issues of neurobiological studies of face perception. Human Neurobiology, 3, 191-196.

Maltzman, I. (1979). Orienting reflexes and classical conditioning in humans. In H. D. Kimmel, E. H. van Olst, \& J. F. Orlebeke (Eds.), The orienting reflex in humans (pp. 201-223). Hillsdale, NJ: Erlbaum.

Perrett, D. I., Smith, P. A. J., Potter, D. D., Mistlin, A. J., Head, A. S., Milner, A. D., \& Jeeves, M A. (1984). Neurons responsive to faces in the temporal cortex: Studies of functional organization, sensitivity to identity and relation to perception. Human Neurobiology. 3. 197-208.

Rolls, E. T. (1984). Neurons in the cortex of the temporal lobe and in the amygdala of the monkey with responses selective for faces. Human Neurobiologv, 3, 209-222.

Rosenfeld, S. A.. \& van Hoesen, G. W. (1979). Face recognition in the rhesus monkey. Neumpsychologia. 17, 503-509.

Sackett, G., Griffin. G. A., Pratt, C., Joslyn, W. D., \& Ruppenthal, G. (1967). Mother-infant and adult female choice behavior in rhesus monkeys after various rearing experiences. Journal of Comparative and Physiological Psychology, 63, 376-381.

Sands, S. F.. Lincoln, C. E., \& Wright, A. A. (1982). Pictorial similarity judgments and the organization of visual memory in the rhesus monkey. Journal of Experimental Psychology: General, 111, 369389.

Tranel, D. Fowles, D. C., \& Damasio, A. R. (1985). Electrodermal discrimination of familiar and unfamiliar faces: A methodology. Psychiophysiology, 22, 403-408.

Weisbard, C., \& Graham, F. K. (1971). Heart-rate change as a component of the orienting response in monkeys. Journal of Comparative and Physiological Psychology, 76, 74-83. 